\title{
A PROTEÇÃO DO MEIO AMBIENTE E A CONSEQUENTE MANUTENÇÃO DA VIDA HUMANA
}

\author{
THE ENVIRONMENTAL PROTECTION AND THE \\ CONSEQUENT MAINTENANCE OF LIFE
}

\author{
Álvaro Suchodolak ${ }^{1}$ \\ Bruno Feitosa ${ }^{2}$ \\ Felipe Hiromi Westphal ${ }^{3}$
}

\begin{abstract}
RESUMO: Este artigo coloca em pauta o porquê do direito ambiental ser considerado um direito difuso, juntamente com isso uma das origens das ações antropomórficas (e também antropocêntricas) que até hoje afetam o meio ambiente e aponta saídas para a degradação ambiental como a implantação de um Estado de Direito Ambiental que abranja todo o mundo. Também é defendido uma participação mais efetiva das sociedades em geral para garantir mais direitos individuais e coletivos pelos quais diminuiria o domínio do poder estatal e o mercantil, que tem degradado por tanto tempo o meio ambiente e os menos favorecidos. Ao final do artigo é exposto um depoimento retirado da revista "Crônicas de Los Tiempos",de abril de 2002 na qual o autor descreve como será na sua visão o mundo em 2070, se não mudarmos o modo de vida predatório pelo qual muitas nações tomam por natural delas.
\end{abstract}

Palavra-Chave: Direito Difuso, Degradação Ambiental, Estado de Direito Ambiental.

\begin{abstract}
This article seeks the reason for the environmental law being considered right diffuse, along with that of the origins of anthropomorphic actions (and anthropocentric) that still affect the environment and shows solutions to environmental degradation as the implementation of an Environmental State of Law covering the whole world. It is also argued for a more effective participation of society in general to ensure more individual and collective rights for which diminish the domain of state power and business, which has for so long degraded the environment and the poor. At the end of the article is exposed a deposition taken from the magazine "Crônicas de Los Tiempos", April 2002, in which the author describes how his vision will be in the world in 2070 , unless we change the predatory way of life by which many nations take feel natural.
\end{abstract}

Palavra-Chave: Diffuse right, environmental degradation, Environmental State of Law.

1 Graduando em Direito pela UEL, suchodolak@pop.com.br

2 Graduando em Direito pela UEL, brunofeitosa@hotmail.com

3 Graduando em Direito pela UEL, felipehiromi@gmail.com 


\section{INTRODUÇÃO}

O meio ambiente, antes considerado bem de ninguém, hoje é um bem de todos, devido à maior representatividade que a Constituição Federal de 1988 deu ao antes quase inexistente Direito Ambiental com o seu artigo $225^{\circ}$. Definiu o meio ambiente ecologicamente equilibrado como um bem de uso comum do povo (direito de todos) e essencial à sadia qualidade de vida, dividindo entre o Poder Público e os cidadãos o dever de protegê-lo e preservá-lo para as presentes e futuras gerações.

Devido a isso, o meio ambiente é considerado um bem difuso, porque seu titular não pode ser determinado, abrangendo um grande e variado número de pessoas. O Direito Ambiental brasileiro é considerado um dos mais evoluídos do mundo; por ser desenvolvido pela conscientização do governo e da sociedade, que buscam diminuir e prevenir o avanço da degradação ambiental. A prova disso é que, atualmente, nas três esferas governamentais, encontramos uma legislação diversificada sobre o controle da poluição, recursos hídricos, conservação e preservação da fauna e flora, uso do solo, educação ambiental, estímulo ao desenvolvimento sustentável, combate aos crimes ambientais e outros temas afins.

Contudo, só a legislação brasileira não é o bastante para minimizar os descasos com o meio ambiente ao ponto necessário para a sobrevivência da espécie humana nos próximos séculos sem nenhum dano drástico no modo de vida das pessoas, pois não há como impedir a poluição de um Estado de afetar a organização política e jurídica da sociedade brasileira nem ela de prejudicar outro país; lembrando que o Brasil ainda deixa a desejar concernente às questões ambientais (verifica-se a contribuição brasileira de 3\% da poluição ambiental). A origem do problema ambiental está no fato de como a humanidade vê e entende o mundo, assunto que será mais explanado nas próximas páginas.

\section{A PROTEÇÃo do MEIO AMbIENTE E A CONSEQÜENTE MANUTENÇÃo DA VIDA HUMANA}

A questão ambiental tem se tornado cada vez mais relevante devido à percepção humana das limitações da natureza após as conseqüências desastrosas ocasionadas pela ação irracional do homem. Diversos foram e são os motivos pelos quais houve a ignorância em relação aos recursos naturais, entre eles: ausência de qualidade de vida para a sociedade mundial, o que implica má gerência e a defesa de interesses egoístas por partes daqueles que possuem 
incumbência em realizá-la, o que demonstra descomprometimento das autoridades, falta de conscientização ambiental, portanto, inexistência de educação ambiental, não realização efetiva das leis, teorias projetos ambientais, etc. Afinal, proteger o ambiente significa a proteção da humanidade.

\section{Princípio da dignidade humana}

Em países em que nem mesmo a dignidade humana está sendo respeitada pela organização política e jurídica da sociedade, ou precisamente, os agentes; planejar e por em prática a fiscalização e permitir o uso adequados dos recursos naturais torna-se uma utopia. Quando se fala na dignidade da pessoa humana, como está colocada no art. $1^{\circ}$, III da Constituição Federal, representa educação pública de qualidade com a formação de cidadãos críticos e conscientes dos seus direitos e deveres na sociedade, o aprendizado e a prática dos valores morais, representam também saúde pública de qualidade, moradia digna, enfim, todos os direitos individuais e principalmente sociais com o objetivo da criação de comunidades justas, solidárias. Portanto, não se pode realizar uma cisão ou simplesmente analisar isoladamente os conflitos relativos às questões social-ambientais, pois ambas estão intrinsecamente ligadas.

\section{A questão do sujeito e do objeto}

Apesar da convicção da coesão das questões social-ambientais, sua compreensão gera equívocos. Assuntos que dizem respeito ao ambiente são complexos exatamente por que possíveis soluções dependem da resolução de diversas variáveis. Um dos maiores erros seria pensar a solução das questões sociais a significar definitivamente solução das questões ambientais. Como foi dito, o tema traz diversas variáveis conflitantes e uma delas coloca a tese socialambiental em contradição, cujo fator são os interesses egoístas, ou para ser mais explícito, o ser humano é o sujeito e todo o resto, portanto, meros objetos a disposição dos homens. As pessoas são assim chamadas por que elas constituem as finalidades em si mesmas. Diferentemente dos objetos, cuja função é o meio para atingir a finalidade. (Kant, 1785)

Neste exposto evidencia-se a diferença entre sujeito e objeto, e quem tem sido usado como objeto há muito tempo na história da humanidade é a natureza. Usam-na e exploram-na conforme o desejo do sujeito. Nesta teoria prática deixa-se a desejar no sentido de colocar o ambiente como instrumento da mesma forma como puseram a razão e a ciência sendo meios da 
classe detentora do capital.

Um novo paradigma teórico-prático deve ser elaborado a colocar a vida humana, vegetal, animal, em primeiro plano. A natureza precisa urgentemente de um projeto em que seja vista como um fim em si mesma, mas não como meio para o fim. Os filósofos Emmanuel Kant, René Descartes, quando formularam suas teorias não tiveram preocupação com as teses ambientais até porque não se tinha visto, até aquele momento, as manifestações do planeta cujas reações decorreram das atividades humanas em pleno descaso em relação ao meio. A clareza é uma das virtudes para se colocar a teoria em sua praticidade, portanto, ao propor um exposto intelectual, cuja posição e consideração do meio ambiente é um fim em si mesmo, não quer dizer a não exploração plena do mesmo, e sim a valorização juntamente com o uso racional. Mesmo porque sem exploração dos recursos naturais a possibilidade concreta de desenvolvimento praticamente inexiste.

Ainda a tratar da teoria-prática sujeito-objeto se faz necessário, devido aos novos conflitos da contemporaneidade, dizer a respeito da "coisificação" dos seres humanos a provocar maiores dificuldades da valorização ambiental. A síntese do pensamento coloca a seguinte questão: se nem o ser humano, nas sociedades de consumo, é tratado como sujeito, não em plenitude, todavia os que vendem sua força de trabalho, quanto a natureza, vê-la sujeito parece distante de acontecer. A fiscalização do pensamento teorético se traduz como sendo a exploração das classes privilegiadas manifestada a tudo e todos não se refletindo a respeito das conseqüências da exploração desmedida, inconseqüente. Logo, torna-se fácil deduzir que a mudança de atitude somente virá a acontecer quando os donos dos meios de produção sentirem os efeitos catastróficos do uso egoísta dos recursos naturais tendo ciência de que se originam das suas próprias atividades.

\section{O que fazer para proteger 0 meio ambiente?}

Uma das saídas de proteção ambiental é a construção do Estado de Direito Ambiental, todavia a idéia que pode virar realidade encontra obstáculos consideráveis. Primeiramente o próprio estado mostra maior ênfase ao crescimento econômico do que o desenvolvimento econômico sustentável, além disso a instituição de normas jurídicas precisa ser complementada com educação ambiental, qualidade de vida à população, mudança dos hábitos da sociedade de consumo, principalmente dos países desenvolvidos em especial os Estados Unidos. A formação de blocos econômicos entre eles; União Européia, Mercosul, Nafta e demais, tem demonstrado 
por parte dos Estados, relevância maior das questões relacionadas ao comércio, crescimento econômico do que temas ligados ao meio ambiente. Até porque a origem da formação dos blocos já tinha objetivos econômicos. Hoje, estas instituições discutem muito em suas reuniões sobre proteção, conservação, preservação do espaço ambiental. (Wolkmer, 2003)

Reconhece na humanidade os seres mais inteligentes, sábios do planeta Terra, entretanto a contradição é inerente aos humanos ocorrendo sabedoria e ignorância no mesmo ser. Ao fazer uma retrospectiva na época dos confrontos entre o homem branco e os indígenas, percebeu-se a ocorrência da imposição de valores, etnocentrismo, dos brancos em relação aos nativos, o que evidencia a contradição, pois os povos europeus quando chegaram ao continente americano, se julgaram superiores devido a tecnologia, ciência, ao mesmo tempo, com relação a saber viver harmoniosamente ao lado da natureza, eram inferiores na comparação silvícola. Os povos considerados primitivos no decorrer de sua história souberam cuidar da área natural a considerá-la sagrada, pois dela obtinham a sobrevivência. O que não aconteceu com os povos considerados evolucionários; estes começaram a valorizar seu espaço físico após sentir as conseqüências advindas do processo degradatório. Mesmo posteriormente aos resultados desagradáveis as atitudes não mudaram plenamente e o maior exemplo são os estadunidenses, cujo Tratado de Kyoto recusaram-se a assinar.

As questões conflituosas obrigam a sociedade a refletir, propor teorias efetivas em que boas idéias começam a surgir. Basta o maior uso da razão para encontrar métodos que, se aplicados, resolveriam difíceis casos. O planeta Terra precisa ser salvo do próprio homem e se as idéias não forem postas em prática, as previsões do Apocalipse serão concretizadas a chegar em um estágio irreversível do qual as anteriores boas idéias não mais qualificar-se-ão boas, e sim ineficazes, porque as belas teorias não passam de belas teorias, como se a sociedade fosse composta de homens, mulheres, filósofos a colocá-las em um mundo distante da Terra, o mundo das essências preconizado por Platão.

\section{OUTRA SAÍDA NO QUE CONCERNE O MEIO AMBIENTE}

A voltar à realidade a respeito das idéias, coloca-se a participação efetiva da sociedade a garantir mais direitos e deveres individuais, coletivos. A síntese da proposta consiste em mais cidadania, mais sociedade e menos Estado e menos mercantilização. Afinal, defender o ambiente interessa a todos, faz-se necessário a ação conjunta de todos. Analisando esta refle- 
xão anterior, compõem-se outra tese; legislação ambiental universal. Parte-se do princípio da não-eficácia quando existem diversas legislações ambientais distintas a comprometer o meio como um todo. A Floresta Amazônica não pertence exclusivamente ao Brasil, logo, a necessidade de uma legislação supranacional. O principal entrave a esta idéia sensacional é a questão da soberania. Um princípio precisa imediatamente considerado o maior de todos e quaisquer países devem integrá-lo aos seus ordenamentos jurídicos; este princípio é a vida. Nada pode estar acima dela. Portanto, a instituição de legislações ambientais universal significa instituir a própria conservação da vida não só humana, mas também animal e vegetal, pois elas estão inter-relacionadas, interdependentes, todavia o homem depende mais da natureza do que a natureza dele. (Soares, 2003)

Antes de surgir pessoas, a vida animal e vegetal já existiam. O que leva a inferência de que a extinção da humanidade não resultaria na extinção dos animais e vegetais. Percebe-se o equívoco da colocação dos termos inter-relacionados, interdependentes que, entretanto, não considerados absolutamente, e sim de forma relativa, justificam-se levando em consideração a não extinção dos recursos naturais, animais, plantas, por parte dos homens. A natureza depende dos homens para que permaneça a existir. Enfim, a sobrevivência do homem depende da sobrevivência da natureza o que inversamente também se pode dizer. Enquanto não houver a solução de todas as variáveis conflitantes, anteriormente expostas, a humanidade terá um destino irreversível, incontrolável a compromete o futuro das novas gerações.

Este possível futuro foi descrito de forma até exagerada por um texto publicado na revista "Crônicas de Los Tiempos", de Abril de 2002 em que começa com o homem descrevendo o ano 2070. (Ellwanger, 2002)

\footnotetext{
Acabo de completar 50 anos, mas a minha aparência é de alguém de 85 . Tenho sérios problemas renais porque bebo pouca água. Creio que me resta pouco tempo. Hoje sou uma das pessoas mais idosas nesta sociedade. Recordo quando tinha 5 anos. Tudo era muito diferente. Havia muitas árvores nos parques. As casas tinham bonitos jardins e eu podia desfrutar de um banho de chuveiro por aproximadamente uma hora. Agora usamos toalhas em azeite mineral para limpar a pele. Antes, todas as mulheres mostravam as suas formosas cabeleireiras. Agora, raspamos a cabeça para mantê-la limpa sem água. Antes, meu pai lavava o carro com a água que saía de uma mangueira. Hoje os meninos não acreditam que utilizávamos a água dessa forma. Recordo que havia muitos anúncios que diziam para cuidar da água, só que ninguém lhes dava a devida atenção. Pensávamos que a água jamais poderia terminar. Agora, todos os rios, barragens, lagoas e mantos aquíferos estão irreversivelmente contaminados ou esgotados. Imensos desertos constituem a paisagem que nos rodeia por todos os lados. As infecções gastrointestinais. enfermidades da pele são as principais causas de morte. A
} 
indústria está paralisada e o desemprego é dramático. As fábricas dessalinizadoras são as principais fontes de emprego e pagam os empregados com água potável em vez de salário. Os assaltos por um bujão de água são comuns nas ruas desertas. A comida é $80 \%$ sintética. Antes, a quantidade de água indicada como ideal para se beber era oito copos por dia, por pessoa adulta. Hoje só posso beber meio copo. A roupa é descartável, o que aumenta grandemente a quantidade de lixo. Tivemos que voltar a usar as fossas sépticas como no século passado porque a rede de esgoto não funciona mais por falta de água. A aparência da população é horrorosa: corpos desfalecidos, enrugados pela desidratação, cheios de chagas na pele pelos raios ultravioletas que já não tem a capa de ozônio que os filtrava na atmosfera. Com o ressecamento da pele, uma jovem de 20 anos aparenta ter 40. Os cientistas investigam, mas não há solução possível. Não se pode fabricar água, o oxigênio também está degradado por falta de árvores, o que diminui o coeficiente intelectual das novas gerações. Alterou-se a morfologia dos espermatozóides de muitos indivíduos. Como conseqüência, há muitas crianças com insuficiências, mutações e deformações. O governo até nos cobra pelo ar que respiramos: $137 \mathrm{~m}^{3}$ por dia por habitante adulto. Quem não pode pagar é retirado das "zonas ventiladas", que estão dotadas de gigantescos pulmões mecânicos que funcionam com energia solar. Não são de boa qualidade, mas se pode respirar. A idade média é de 35 anos. Em alguns países restam manchas de vegetação com o seu respectivo rio que é fortemente vigiado pelo exército. A água tornou-se um tesouro muito cobiçado, mais do que o ouro ou os diamantes. Aqui não há árvores porque quase nunca chove. $\mathrm{E}$ quando chega a ocorrer uma precipitação, é de chuva ácida. As estações do ano foram severamente transformadas pelas provas atômicas e pela poluição das indústrias do século XX. Advertiam que era preciso cuidar do meio ambiente, mas ninguém fez caso. Quando a minha filha me pede que lhe fale de quando era jovem, descrevo o quão bonito eram os bosques, falo da chuva e das flores, do agradável que era tomar banho e poder pescar nos rios e barragens, beber toda a água que quisesse. O quanto nós éramos saudáveis. Ela perguntava-me: - Papai! Por que a água acabou? Então, sinto um nó na garganta! Não posso deixar de me sentir culpado porque pertenço à geração que acabou de destruir o meio ambiente, sem prestar atenção a tantos avisos. Agora, nossos filhos pagam um alto preço... Sinceramente, creio que a vida na Terra já não será possível dentro de muito pouco tempo porque a destruição do meio ambiente chegou a um ponto irreversível. Como gostaria de voltar atrás e fazer com que toda a humanidade compreendesse isto enquanto ainda é possível fazer algo para salvar o nosso planeta Terra.

\section{CONCLUSÃO}

Nem todos os povos precisaram sentir as conseqüências negativas advindas do processo degradatório para começar emergir das suas mentes a consciência, e a maior prova foram os nativos da América, não somente eles, que consideraram a natureza sacra sabendo explorá-la e deram o devido valor. A maior parte da humanidade encantada com os resultados da razão e da Ciência não se deu conta do principal elemento responsável por toda a evolução cientifica, tec- 
nológica, e da necessidade de saber usa lá. A pergunta mais certa a ser feita; Quem é realmente superior no que diz respeito a saber utilizar os recursos naturais? O fato relacionado com o meio nos diz como os seres mais inteligentes do planeta Terra tornaram-se os mais ignorantes, irracionais, mesquinhos quando, pela busca da maior quantidade de capital e conforto possível, não analisaram o maior bem responsável pelo progresso da humanidade. Neste sentido, o sistema Capitalista tem papel preponderantemente, pois a filosofia da relevância do ter em detrimento do ser expandiu-se por diversas esferas da sociedade. Basta fazer uma analise não tão profunda e ficará evidente o que o ser humano torna-se capaz de fazer para obter riquezas.

Portanto, o que precisa ser feito para mudar esta realidade e não se chegar ao ponto irreversível descrito pela revista, "Crônicas de Los Tiempos", mesmo com certos exageros, é a erradicação das questões sociais e mudar o caráter da pessoa humana através da educação, oportunidade de emprego, todavia, principalmente moldar o atual sistema Capitalista pelo qual tem conduzido as pessoas a características egoístas cada vez mais profundas fazendo com que elas se vejam concorrentes e até mesmo inimigas uma das outras.

\section{REFERÊNCIAS BIBLIOGRÁFICAS}

WOLKMER, Antonio Carlos; MORATO LEITE, José Rubens. Os "novos" direitos no Brasil: Natureza e perspectivas: uma visão básica das novas conflituosidades jurídicas. São Paulo: Saraiva, 2003.

KANT, Emmanuel. Fundamentação da metafisica dos costumes. 7. ed. Portugal: Lisboa.

SOARES, Guido Fernando Silva. A Proteção Internacional do Meio Ambiente. São Paulo: Manole LTDA.

ELLWANGER, Ria. Cronica de Los Tiempos, Buenos Aires: 2002. 